\title{
FEIJOO Y ALEMANIA: LAS TRADUCCIONES PARCIALES DE SUS OBRAS EN LA ALEMANIA DEL SIGLO XVIII
}

Todavía no se ha estudiado de manera sistemática la recepción de Feijoo en la Europa ilustrada. No se han analizado ni siquiera las traducciones -en general parciales - de sus obras, cuya existencia habia sido puesta de relieve por el mismo Feijoo ${ }^{1}$. Existen, sin embargo, indicaciones bibliográficas que podrían formar la base de tales estudios. Bástenos indicar las enumeraciones de Morayta, de Delpy y la valiosa bibliografía de Silverio Cerra Suárez ${ }^{2}$. Últimamente, Agustín Coletes Blanco ha intentado la investigación sistemática de las traducciones inglesas ${ }^{3}$; ofrese una buena bibliografía comentada. No existe nada semejante en cuanto a las traducciones francesas ${ }^{4}$ o alemanas.

La «suma» reciente de las relaciones literarias entre Alemania y España no menciona siquiera a Feijoo (ni a Isla ni a Clavijo tampoco) ${ }^{5}$.

Nuestra nota se limitará a presentar y comentar brevemente las traducciones alemanas que se han hecho de las obras feijonianas durante el si-

1 Cartas Eruditas, III, 14 (1750). La traducción al alemán que Feijoo no había visto y que suponía hecha por Schomberg no existe.

2 «Doscientos cincuenta años de bibliografía feijonianan, en Studium Ovetense, 4, 1976. $329-494$.

3 «Notas sobre la influencia de Feijoo en Inglaterra: algunas traducciones y menciones), en BOCES.XVIII, 3, 1975, 19-54.

4 R. Rancoueur se limita a repetir las indicaciones bibliográficas hechas por Delpy en 1936. (Cf. «Feijoo en Francia), en Yermo, 2, 1965, 273-293).

5 Gerhart Hoffmeister, Spanien und Deutschland. Geschichte und Dokumentation der literarischen Beziehungen, Berlín, 1976. 
glo XVIII. Se trata de cinco traducciones parciales, de las cuales Cerra Suárez menciona tres: los números $0.304,0.305,0.306$.

Para el año 1792, Cerra Suárez da la indicación siguiente: Feijoo, B. J.: Traducción al alemán de sus escritos sobre música en Allgemeine Literatur der Musik, Leipzig, 1792, pp. 10 ss. Se trata de una (ghost edition». La indicación no se refiere a una edición de los (!) escritos de Feijoo sobre la música, sino a la bibliografía musicológica de Johann Nicolaus Forkel ${ }^{6}$, donde, en la p. 10, se encuentra la siguiente ficha bibliográfica:

Feijoo, Don, ein Spanier: El Deleyte della Música accompannado de la virtud hace la Tierra el noviciado del Cielo. (Sigue la traducción alemana de este título). Einen Auszug unter dem Titel: Uber den Einflu $\beta$ der Musik auf das monschliche Herz findet man in den Hamburg. Unterhaltungen, Bd. 1, S. 526-33.

El primer tomo de la revista Unterhaltungen de Hamburgo se publicó en 1766. Allí se encuentra efectivamente en el lugar indicado un artículo "Auszug aus einer spanischen Abhandlung des Don Feyjoo über den Einfluß der Musik auf das menschliche Herz). (= «Extracto de un tratado español de Don (!) Feyjoo sobre el influjo de la música en el corazón humano»).

Es esta la primera traducción alemana de un texto de Feijoo, que conozco. No es, sin embargo, la primera mención del benedictino en una revista alemana. Esta parece ser la noticia poco favorable que Mayáns publicó en las Actas Eruditorum, Leipzig, 1731, p. $437^{7}$.

6 Allgemeine Literatur der Musil oder Anleitung zur Kenntniß musikalischer Bücher, welche von den ältesten bis auf die neuesten Zeiten bey den Griechen, Römern und den meisten neueren europäischen Nationen sind geschrieben worden, Leipzig, 1792 (Reprint Hildesheim, 1962).

7 Dice de Feijoo: “Hujus viri lectio fere omnium oculos in Hispania detinet non aliam ob causam, nisi quia gens imperita \& rudis tot argumentorum varietatem admiratur. Quanquam praeditus est Feijoo singulari ingenio, quod nemo ei negat. Philautia maxime laborat. A multis est impetitus; sed, ut debiles adversarios nactus est, eorum impetus irridet, nescius forte, quantum a potenti adversario pati posset, si critico stilo res esset decernenda" (p. 437). Esta valoración bastante negativa no debió excitar en los eruditos alemanes el deseo de conocer la obra de Feijoo de más cerca. 
El texto que no da ninguna información suplementaria sobre el autor Feijoo, es la traducción muy abreviada de la primera carta del tomo IV de las Cartas Eruditas.

La reducción de las 32 páginas del texto español a unas 7 páginas de la versión alemana se consigue por medio de supresiones sistemáticas. El criterio de estas supresiones, lo indica ya la omisión del subtítulo de la Carta: "A una señora devota, y aficiónada a la música». El “caso de conciencia» que dio origen a la carta de Feijoo, - el problema del "afecto a las cosas criadas» entre ellos a la música por parte de una persona devotano le interesa de ninguna manera al traductor alemán. Por consiguiente suprime todo el contexto teológico y toda la argumentación espiritual de Feijoo. Lo que le interesa al traductor es la eminente dignidad y eficacia que Feijoo concede al arte de la música. Pero esta dignidad no consiste para él en el el hecho de que (cel deleyte de la música, acompañado de la virtud, hace en la tierra el noviciado del Cielo».

A él no le interesa sino una visión secularizada de la música. El gran influjo que la música ejerce sobre el corazón humano constituye para él una especie de paraíso mundanal, sin ninguna relación con una vida en el más allá, tal como la coneibe el cristianismo. E1 traductor sustituye la visión teológica de la carta feijoniana por la visión sentimental y secular, típica de la época. Es muy revelador el último párrafo que añade al texto original: «Da die Musik einen so mächtigen und vorheilhaften Einfluß auf unsre Herz hat, wie billig ist nicht unsere Verehrung dieser vortrefflichen Kunst ! er sie verachtet, oder nur gleichgültig gegen sie ist, macht sich allemal eines unempfindlichen Herzens verdächtig») (p. 533).

Se puede decir que el traductor sustituye en su visión iluminada del mundo la religión por el arte de la música, lo que corresponde a la tendencia secularizadora de la época. Pero esta interpretación constituye una perversión completa del texto original de Feijoo, quien — sacado de su argumentación teológica- aparece mucho más (moderno» de lo que era.

Incluso, el traductor critica en una breve nota el concepto central de la armonía, en el sentido global tal que lo emplea Feijoo, concepto que se tacha de paralogismo ${ }^{8}$. En cuanto al personaje del traductor, hay que lamentar que el texto alemán no esté firmado. Sin embargo, se sabe que de los editores de las Unterhaltungen -Daniel Schiebeler y Johannes Joachim

$\$$ P. 528, nota; se refiere a los $\$ \S 18.20$, de la Carta. 
Eschenburg- el primero ha sido buen conocedor de las letras hispánicas y que formaba con Postel y Lessing el núcleo de hispanistas hamburgueses 9. El buen conocimiento de la lengua española que se nota en la traducción de los párrafos no suprimidos, podria indicarle como autor.

\section{II}

La segunda traducción de un texto feijoniano se publicó en 1790. Cito el título completo del libro porque se halla desfigurado en Delpy y Cerra Suárez.

Diätetik / vorzüglich für / Studierende / vom / Pater Feyjoo / General des Benedictiner $=$ Ordens $/$ Aus dem Spanischen im Englische und aus diesem nun / im Teutsche übersetzt nebst den aus vieljähringen Erfahrungen gezogenen / Gesundheitsregeln / Dr. John Fothergill's / und deren diätetische Bemerkungen über den idiopatischen / fixen Kopfsch. merz / verdeutscht und mit Anmerkungen herausgegeben / von / Christian Friedrich Michaelis / Zwittau und Leipzig, bey Johann David Schöps, 1790 .

El libro de más de 300 páginas contiene dos partes netamente separadas: La traducción de los textos de Feijoo (Regeln die Gesundheit zu erhalten, p. 1-140) y la traducción de las «reglas para la salud» (Gesundheitsregeln) de Fothergill (p. 141 ss.).

Aquí solo entra en consideración la primera parte.

El traductor (Chr. Fr. Michaelis - no Michel según transcribe Cerra), médico bien conocido de Leipzig, publicó entre 1785 y 1796 más de 50 tratados médicos traducidos del francés y del inglés ${ }^{10}$.

En el breve prólogo de su traducción Michaelis expresa su admiración por las ideas ilustradas y su aprecio por las ideas médicas de Feijoo. Pero sabe muy poco del autor: que no es médico sino monje español y que cuenta con Ustáriz (!), Campomanes, Ulloa, Mayáns, Flórez e Isla entre los

9 Hoffmeister, Spanien und Deutschland, p. 88.

10 Las traducciones se enumeran en: Meusel, Das gelehrte Teutschland oder Lexiton der jetzt lebenden tutschen Schriftstel, ler. T. 5, Lemgo, 1797, 224-230. 
«hombres eruditos y perspicaces que aspiran la noble libertad», apreciación que saca de una historia universal para niños ${ }^{11}$.

Transcribe también el prólogo del editor inglés que es menos favorable a Feijoo. Se aprecian 'su empirismo y sus consejos prácticos, pero se pone en duda su teoría médica. Según indica el mismo Michaelis, su traducción se basa en la edición de 1787 de la versión de Forthergill ${ }^{12}$.

La traducción alemana comprende tres capítulos.

1. Unzuverlässigkeit der Heilkunde (5-69) que no es, como dice Coletes (p. 49), la traducción de las Paradojas médicas (TCU VIII, 10), sino la traducción de los once párrafos del discurso Medicina (TCU I, 15), sin embargo sin la Adición (Obras, II, BAE, 52-53).

2. Las páginas 70-121 que no llevan título y que son la traducción de los diez párrafos de Régimen para conservar la salud (TCU I, 6).

3. Ermunterung für Gelehrte und Studierende (122-140), traducción de los siete párrafos de Desagravio de la profesión literaria (TCU I, 7).

La traducción alemana es una versión fiel del pensamiento médico de Feijoo, tal como éste lo ha expuesto en el primer tomo del TCU, aunque, por ser la traducción de una traducción, no sigue muchas veces la estructura sintáctica del original.

En cuanto al contenido sólo se notan dos modificaciones: Michaelis adoptó los títulos que Forthergill había dado a los capítulos 1 y $3 ;$ y componiendo un manual práctico, suprime todo el aparato erudito del texto feijoniano, es decir las citas latinas (que muchas veces se traducen) y todas las notas. Desaparece de esta manera el alcance teórico de lo expuesto por Feijoo.

Es prueba de la validez del pensamiento médico de Feijoo el hecho de haber encontrado traductor tan bien informado en asuntos médicos como el doctor Michaelis. Sin embargo, el «descubrimiento» de Feijoo médico no

11 Allgemeine Weltgeschichte für Kinder von Johann Matthias Schröckh, T. IV, 1, Leipzig, 1782, p. 388. Michaelis caracteriza las ideas médicas de Feijoo en una sola frașe: «Man wird in seinem Buch, wie ich glaube, Scharfsinn, und bei einem Grade von Liebe zum Paradoxen, doch auch aufrichtige Wharheitsliebe, und Neigung, nützliche Grundsäzte gemein verständlich zu machen, nicht verkennen können» (p. $+4 \mathrm{r} / \mathrm{v})$.

12. Coletes Blanco no conoce esta edición; sólo menciona una de 1777 (que no ha visto y que Cerra, n. 0.254, cree ser el original de la traducción alemana) y otra de 1800. 
se debe a conocimientos hispanísticos por parte de Michaelis, sino a la autoridad y al prestigio del famoso Fothergill, «important representative of the naturalistic and anti-scholastic tendencies of English medecine in the latter half of the eighteenth century ${ }^{13}$. Sus Rules conocieron 14 ediciones y ya en 1785 se habian publicado dos tomos de sus obras en traducción alemana ${ }^{14}$.

En el texto del anglófilo Michaelis no hay nada que probase una familiaridad con asuntos espanoles o las discusiones - precisamente en aquellos años muy intensos- acerca de la eultura española ${ }^{15}$.

\section{III}

Mejor -aunque no muy bien informado en cuanto a la situación española y al papel de Feijoo como «desengañador de las Españas» era Ludwig Harscher von Almendingen (25.III.1766 en París - † 16.I.1827 en Dillenburg), quien ha dado a luz las siguientes traducciones (hechas sobre el texto español):

1. Ueber die Moden (Aus dem Spanischen). In: Hannoverisches Magazin, 27 tes Stück, Freitag, den 3ten April 1789, col. 418-432.

2. Etwas über philosophische Fehden. In: Hannoverisches Magazin, 39tes Stück, Freitag, den 14tten Mai 1790, col. 609-624.

Estas dos traducciones no se mencionan en la bibliografía de Cerra.

3. Kritik gemeiner Irrthümer von Benito Feyjoo. Erster Band. Aus dem Spanischen übersetzt von L. Harscher von Almendingen. Gotha 1791.

Las tres traducciones son la obra de un joven estudiante, de la universidad - muy hispanista - de Göttingen, quien más tarde llegó a ser uno de

13 The Dictionary of National Biography, London, s.a., T. VII, p. 508 A.

14 Ibid.

15 Cf. B. Becker-Cantarino, "Die 'schwarzeLegende». Zum Spanien hild in der deutschen Literatur des 18. Jahrhunderts), en Deutsche Philologie, 94, 1975, pp. 183-203. Es la época de la fumosa querella acerca de la cultura española provocada por Masson de Morvilliers. La defensa de España por Cavanilles se publicó en 1785 en traducción âle mana, donde (p. 47) se alaba a Mayáns, Isla, Feijoo, Bayer, «que nos devuelven los antiguos tiempos felices, durante los cuales excelentes autores españoles sirvieron de modelo a las demás naciones . 
los más famosos y más discutidos juristas alemanes de la época ${ }^{10}$. Tenía desde muy joven una buena formación lingüística (sabía alemán, francés, latín, italiano, español, inglés, holandés) y disponía de la biblioteca bien nutrida de su padre ${ }^{17}$.

Es él quien intentó revelar sistemáticamente la obra de Feijoo a los lectores alemanes.

Über die Moden es la traducción fiel y bastante completa del discurso Las Modas (TCU II, 6) que Almendingen parece haber escogido por su contenido más bien general y entretenido para una primera presentación del autor español.

En la nota introductoria Almendingen presenta al TCU como «una obra que probablemente es completamente desconocida fuera de España». A Feijoo le presenta como «benedictino erudito de Oviedo». Con su traducción quiere dar una prueba favorable de la literatura española cuya ignorancia por parte de los lectores alemanes no cree justificada. "Schon Cronegk und Lessing haben die Deutschen, — freilich beide aus sehr verschiedenen Rücksichten-, die Kultur dieser vortrefflichen, schon seit Jahrhunderten ausgebildeten, reichen, prächtigen Sprache anempfohlen. Man hätte freilich auf das Wort eines Lessings glauben können, daß in dieser Sprache sehr viel geistvolles und interessantes, über alle jene sittliche und intellektuelle Gegen stande gedacht und gesagt worden, bei welchen der hierarchische Druk (sic) nicht direkt oder indirekt die Schwungkraft des Geistes lähmte» (alusión algo velada a la censura estatal e inquisitorial).

Si la traducción alcanza el aplauso del público alemán, Almendingen quiere traducir «toda la obra de Feyjoo (...), que según mi impresión podría honrar países y épocas a todos respectos más ilustrados). (Welches nach meinem Gefühl unter alle Rücksicht aufgeklärteren Ländern und Zeitperioden Ehre machen würde).

Parece que Almendingen se sirve del texto de Feijoo —que rechaza

16 Cf. Enciclopedia Univ. Ilustrada (Espasa-Calpe), T. IV, p. 816 A. La biografia más completa es la de A. Merker, "Ludwig Harscher von Almendingen. Ein Rechtsgelehrter, Schriftsteller und Staatsmann des beginnenden neunzehnten Jahrhunderts"), en Nassauische Annalen (Wiesbaden), 43, 1914/15, pp. 266-373. Un buen estudio sobre el jurista Almendingen - pero sin referencia a su papel de traductor- es la obra de Elisabeth Fehrenbach, Traditionelle Gesellschaft und revolutionaires Recht. Die Einführung des Code Napoleón in den Rheinbundstaaten, Göttingen, 1974.

17 Merker, Almendingen, p. 270. 
el influjo innovador de la moda francesa- para oponerse a la galofilia excesiva de sus contemporáneos alemanes. En la frase de Saint Evremont citada por Feijoo — «no hay país (...) donde haya menos uso de la razón que en Francia, aunque es verdad que en ninguna parte es más pura que aquella poca que se halla entre nosotros»— el traductor suprime la segunda parte subrayando de esta manera el aspecto antifrancés. Tiene la misma función la nota que Almendingen puso al final del texto:

«So sprach schon im Jahre 1727 ein Mann in finsesteren Iberien dos Verdammungsurtheil über die Deutschen vom vorletzten überfeinen und überhellen Jahrzehend des zu Ende gehenden Jahrhunderts. Leid ist mir für meine Zeitgenossen, daß eine aus dem Schoos der Finsterniß und Barberei hervortönende Stimme ihnen Wahrheit predigen muß. Von daher sollten sie doch wahrhaftig keiner Fackelmehr bedürfen).

La tendencia a dar al texto de Feijoo una nota actual dentro del contexto alemán, se encuentra también en el artículo «Etwas über philosophische Fehden). Es la traducción bastante fiel, aunque no sin algunas omisiones, del discurso "Guerras Filosóficas» (TCU, II, 1). Sin embargo, de los diez párrafos del texto español sólo se han traducido los cinco primeros. De modo que se suprimen los párrafos en los que Feijoo intenta reconciliar la teología católica con el pensamiento de los filósofos modernos cpurados. Lo que a Almendingen interesa es la separación entre teología y filosofía. Por eso aprueba a Feijoo cuando éste se opone a los filósofos que - para rechazar el sistema contrario- se acusan recíprocamente ade ser sus doctrinas incompatibles con los sagrados dogmas». E1 recurso al argumento teológico no debe admitirse en el pensamiento secularizado de la filosofía.

Almendingen subraya la validez de esta visión por una nota que pone a este texto: «Dies sagt ein Benediktiner in Spanien, unter den Augen der Inquisition. Dies, hinzugedacht, kann kein deutscher Leser an dieser Aeußerung ein Aergebnis nehmen. Und nehme ers doch, so wurde ich mit seiner Erlaubnis das wieder philosophische Intoleranz nennen». Se diría que esta nota se dirige contra cierta ortodoxia protestante en Alemania - que, como algunos teólogos enemigos de Feijoo en España-- quería erigirse en juez de asuntos filosóficos y literarios de la época.

Los dos textos que acabamos de examinar han sido integrados por Almendingen en su intento de una traducción más voluminosa del TCU que se publicó con el título «Kritik gemeiner Irrthümer von Benito Feyjoo. Erster Band». (Cf. arriba, n. 3; se trata del n. 0.305 de Cerra), 
El libro contiene la traducción de los siguientes discursos: Vorerinnerung des Verfassers an den Spanischen Leser, p. VIII-XIV ( = Prólogo al lector, TCU I).

1. Glorias de España (TCU IV, 13; texto alemán; p. 1-59).

2. Voz del pueblo (TCU I, 1; p. 61-67).

3. Las Modas (TCU II, 6; p. 68-69).

4. Guerras Filosóficas (TCU II, 1; 90.109).

5. Antipatía de Franceses y Españoles (TCU II, 19; p. 110-123).

6. Reflexiones sobre la Historia (TCU IV, 8; 124-170).

7. Apologías de algunos personajes famosos en la historia (TCU VI, 6) con un extracto de $U$ so de la mágica (TCU II, 5; p. 171-196).

8. El purgatorio de San Patricio (TCU VII, 6; p. 119-219).

9. Virtud y Vicio (TCU I, 2; p. 220-232).

10. Humilde y alta Fortuna (TCU I, 3; p. 233-256).

11. La política más fina (TCU I, 4; p. 257-296); y

12. Carta de un religioso a una hermana suya, exhortándola a que prefiriese el estado de religiosa al de casada (TCU I, 2).

El contenido de la traducción proviene exclusivamente del TCU de modo que es erróneo llamarla "traducción al alemán de una selección del Teatro critico y de las Cartas Eruditas» (Cerra, 404) o, según Pérez-Rioja, “la traducción germana, reducida, del Teatro y de gran parte (!) de las Cartas ${ }^{18}$.

El volumen está precedido por un breve prólogo del joven traductor (sólo tenía 25 años) (p. III-VIII).

Elogia a Feijoo llamándole «el autor más ilustrado, más filosófico y más razonable)s que la España de los principios del siglo XVIII ha conocido (III). De la obra feijoniana sólo menciona la «primera parte», los tomos I-VIII del TCU que fecha equivocadamente entre 1727 y 1734.

Con el TCU, Feijoo «guerreaba contra los prejuicios, se oponía a la gran oscuridad espiritual que reinaba en su patria, propugnaba la filosofía popular, la tolerancia y la razón sana» (III / IV).

18 J. A. Pérez Rioja, Proyección y actualidad de Feijoo. Ensayo de interpretación. Madrid, 1965 , p. 144. 
Según Almendingen, en Feijoo se reúne la erudición universal con la predilección por conocimientos provenientes de paises extranjeros, sobre todo de la "más reciente literatura inglesa». "Me dolía el hecho de que un hombre tan benemérito de la cultura de una de las naciones más interesantes y más dignas de Europa fuese completamente desconocido en el extranjero, en Alemania, y me decidi a traducir algunos trozos de su obra. (...) Quisiera que este intento llamase una mayor atención sobre la literatura española que contiene tesoros para el espiritu humano y que es más digna de uuestra atención que la literafura de la nueva Italia). (IV). Suprime en su traducción todo lo que Feijoo tenía que sacrificar al «gusto y al modo de pensar de su época y de su público, las numerosas citaciones de los padres de la iglesia (1) y, alguna vez, de los clásicos romanos, las digresiones excesivas que se refieren a asuntos totalmente heterogéneos. No sigue ningún orden expositivo, puesto que no halla ninguno en Feijoo. Lo que sin embargo admira es el acarácter y la dignidad del estilos del TCU que, por falta de diccionarios y de una tradición bien establecida de intercambios intelectuales entre España y Alemania, sólo pueden imitarse con dificultad. Previene al lector alemán, quizás demasiado exigente de que pudiera topar con algunos párrafos que se oponen a su gusto y a su ilustración: le ruega no se olvide jamás de que estả hablando en el texto «un español, un general (1) de la orden benedictina en el año 1726. que exagera por ejemplo los méritos de Teodosio epor ser español y eristianon (VII).

Almendingen termina su prólogo exponiendo el proyecto de un segundo tomo que contendría la biografía de Feijoo sacada de la Biblioteca de escri. tores españoles desde (1) Carlos III de Pérez (1) y Sempere y el aparato critico con notas solve los autores citados por Feijoo. Este tomo no se ha publicado jamás. Tampoco se publicaron los (tomos siguientes) destinados a dar muestras del pensamiento físico de Feijoo a los que Almendingen alude en una nota de la página $\mathrm{X}$.

En su conjunto, el prólogo del traductor expresa el orgullo de Almendingen por haber (descubierto» a Feijoo y la literatura más o mẹnos contemporánea de España.

Pero al mismo tiempo se nota su preocupación por cierto retraso o falta de actualidad del pensamiento feijoniano dentro del contexto europeo y alemán. A veces el mismo Almendingen parece considerar su traducción más bien como mera muestra documentaria del desarrollo intelectual de España y no como contribución valiosa al progreso de la "conciencia europea» (Paul Hazard). No ha llegado todavía la hora del romanticismo que verá en la España del Siglo de Oro la encarnación de su mundo ideal. 
La impresión de cierta "visión exótica» de España resulta también de algunas de las notas explicativas que Almendingen ha puesto al texto de Feijoo. Todo el capítulo XII (Einladung an meine Schewester ins Kloster) - que erróneamente da a entender que se trata de una hermana corporal de Feijoo- acentúa este aspecto. Dice Almendingen en su nota inicial “Lo extraño del tema me perdonará el haber incluido también este discurso en mi colección». Elogia el estilo de la carta (incluso alega algunos párrafos en lengua española) y el análisis sicológico de la vida doméstica que le parece tan justo «que se le perdona de buen grado al autor la falsedad para la que gasta tanto conocimiento de la naturaleza humana y tanto saber artístico» (297). El traductor protestante y futuro jurista, no comparte la interpretación dogmática de la vida del alma, pero se limita a constatar: “Sin embargo he dejado argüir con paciencia al buen padre Feijoo, estando muy seguro de que su falta de lógica (Unlogik) no necesita ser corregida» (210). Para terminar pide en una nota final que no se atribuya al traductor los conceptos erróneos del religioso Feijoo acerca del matrimonio y de sus cuitas (212).

A pesar de la discrepancia ideológica entre el autor, religioso benedictino, y su traductor, joven ilustrado con formación secularizada, la traducción es, en general bastante fiel y no deforma el pensamiento del autor. Sin embargo el conjunto del tomo primero y único de la traducción, da una imagen demasiado estrecha de Feijoo. Reservando los discursos físicos (y quizás médicos) a posibles tomos futuros, Almendingen presenta exclusivamente el pensamiento "histórico» de Feijoo, lo que no refleja bien el verdadero papel del benedictino en el marco de la cultura española.

Bien es verdad que Almendingen, además de suprimir muchas citaciones cuyo valor argumentativo y cuya función estilística rechaza, abrevia en muchos casos el texto de Feijoo, sin que se puedan constatar en todos los casos las razones de su procedimiento.

Empieza la traducción con un discurso «típico», «las glorias de España) que sirve a Almendingen para dar a sus lectores una visión favorable de España, aunque no comparte la visión demasiado favorable de la tradicional "leyenda blanca» que, comentando el texto de Feijoo, califica de hiperbólica. Del mismo modo suprime párrafos enteros que relatan los «milagros militares de Santiago y de san Millán». Lo hace para «no ofender la razón de sus lectores» (47, nota); modifica algunas valoraciones de Feijoo: no acepta su visión demasiado favorable de Fernando el Católico (54) ni su interpretación positiva de la conquista de América. Por no compartir las ideas de Feijoo, acerca del comportamiento de los españoles con los indios, 
Almendingen no continúa su traducción más allá del $\$ 23$ do la primera parte de las "Glorias", añade en nota que «no quiero ni puedo seguir a Feijoo más allá. Pues se permite una apología de las barbaridades que los eastellanos cometieron en América. Falsifica hechos, rechaza autoridades, se pexmite exposiciones ahistóricas para disculpar a sus compatriotas n (59). Reprocha a Feijoo una posición partidaria y teme ofender a la Humanidad entera, si siguiese con la traducción del texto completo que llama aveneno».

Suprime igualmente toda la segunda parte de las “Glorias» que refieren los méritos intelectuales de los españoles a través de los tiempos, méritos que Almendimgen, no contagiado todavía por el entusiasmo romántico por la España religiosa, parece no apreciar en demasía y no cree poder presen. tar a un público más bien prevenido contra España.

Sigue, después de esa “introducción castiza», la traducción parcial del discurso básico del TCU «Voz del pueblo». Sólo se traducen los dos primeros parrafos y la mitad del tereero. Se omite la multitud de ejemplos sa. cados de la historia profana y sacra, así como la discusión de los aspectos teológicos de la cuestión $(\$ \$ 3-8)$. Es el pensamiento de Feijoo el que se lee en la traducción, pero es un pensamiento moderno, secularizado.

Los discursos sobre "Las Modas» y las "Guerras filosóficas» son copias fieles de los artículos respectivos publicados en el Hannover. Magazin. E1 discurso sobre «Antipatia .... se ha traducido integramente; pero Almendingen declara en algunas notas que no comparte los conceptos básicos de Feijoo. Prefiere hablar, en su traducción. de la asi Llamada, la pretendida antipatía de los pueblos. Además moderniza (ceuropeiza») el pensamiento del monje español por la supresión de dos alusiones despectivas a la religión islámiea (recuérdese que el Nathem de Lessing con su propaganda de la tolerancia data de ;1779!).

De las «Reflexiones sobre la historia» sólo se traduce la parte metodológica y se omiten los muchos ejemplos ilustrativos (\$\$ XVI ssqq.) asi como el resumen $(\$ \S X L I I-X L V)$. Los n, VII y VIII de la traducción (Apologías y San Patricio) se presentan como casos concretos del método crítico de Feijoo. En ambos discursos se reduce rigurosamente el número de los ejem. plos. De las numerosas apologias sólo se dan las de Fimpédocles, de Plinio el Mayor, de Apuleyo y del abad Juan Tritemio (TCU II. D. 5, n. 38 ssqq.). En cuanto al purgatorio de San Patricion, Almendingen se limita a traducir los meros hechos por razones de curiosidad más o menos erudita $(\$ \$ 1.4$ y parte de los $\$ \S 6$ y 9). Omite la discusión crítica del fenómeno porque le parece absolutamente superflua. Para el protestante ilustrado el engaño de 
la credulidad de los hombres por parte de los religiosos es evidente y no necesita pruebas. La seriedad con la cual Feijoo desmitifica el pretendido purgatorio es para el traductor, según dice en una nota, muestra del estado poco avanzado de las luces en España (p. 199).

También al traducir el discurso "Virtud y Vicio» Almendingen disculpa las ideas algo envejecidas de Feijoo. Añade en nota que ha modernizado el pensamiento del texto original para quitarle su «olor añejo». No obstante teme que "la moral (feijoniana) parezca una moral trivial y sin sabor al gusto refinado del lector alemán» (p. 220). Resumiendo todos los cambios y omisiones hay que constatar, aquí también, una secularización de las ideas del autor español. No se han traducido los ejemplos bíblicos ni su interpretación alegórica. Se han omitido todos los rasgos de predicación barroca tan presentes en este discurso. La virtud ya no es para Almendingen una categoría religiosa. Es prueba del cambio total de la mentalidad el hecho de que Almendingen ya no puede tomar en serio la famosa y ya citada "Carta ...) que forma parte integral del discurso "Virtud y Vicio» (ed. BAE II, p. 14-18). Aunque la traduce intrgramente y le da una posición bastante marcada todo al final de su libro (p. 297-312), no le concede ningún valor argumentativo. La considera como mero ejemplo de la capacidad retórica de Feijoo. Por eso da un tono muy poético a su traducción a veces bastante libre, e, incluso, cita algunos fragmentos del texto español para dar muestras de su valor poético. La exhortación religiosa se ha convertido en algo exótico y meramente estético, cuyo fondo sicológico e ideológico es completamente equivocado, puesto que desconoce la naturaleza del género humano (nota final del traductor). Almendingen no comparte tampoco la valoración de los bienes terrenales por parte del benedictino español. En su versión deI TCU I, 3 (Humilde y alta fortuna) sólo expone la miseria de los ricos ( $\S I-V I I I)$, pero omite el elogio positivo de la pobreza ( $\S I X-X I I)$, ideal más bien ascético. Aprueba y traduce el rechazo del maquiavelismo por parte de Feijoo (TCU I, 4), aunque omite el elogio del papa Sixto V ( $\S$ XIII) y otros ejemplos sacados de la historia sacra. Estas omisiones quitan el fondo teológico a las ideas políticas de Feijoo y les dan un tono burgués y secularizado que no se encuentra en el original.

En resumen, hay que conceder a Almendingen el mérito de haber traducido bien, con fidelidad y casi sin faltas 13 textos de los diferentes tomos del TCU. Sin embargo las numerosas omisiones revelan la intención bien determinada del traductor de modernizar el pensamiento de Feijoo. No se traducen muchos detalles que ya no constituyen (errores comunes» para el lector ilustrado alemán. Desde luego, Almendingen no quicre dar una vi- 
sión demasiado desfavorable de la literatura ilustrada en España cuyo descubridor alemán se jacta de ser. Pero la modernización más decisiva de las ideas de Feijoo la constituyen las supresiones casi sistemáticas de su fondo doctrinal religioso y católico. Siguiendo las investigaciones ejemplares de Bernhard Groethuysen se podría hablar de la tendencia hacia un emburguesamiento del pensamiento de Feijoo.

En cuanto al criterio de la selección por parte de Almendingen, se nota en seguida que el traductor se ha limitado exclusivamente a los discursos de crítica ideológica general y a la presentación de algunos asuntos considerados como típicamente españoles. No se ha traducido ninguno de los discursos de asunto médico o físico, lo que escamotea el aspecto empírico tan importante en el pensamiento de Feijoo. Almendingen consideraba su traducción no como importante contribución o fomento de las luces en Alemania (al igual de la traducción de obras francesas), sino como información sobre el estado de la ilustración en España, cuya existencia quería subrayar frente al desconocimiento y a la propaganda anti-española. Al mismo tiempo Almendingen parece querer oponer su descubrimiento de la literatura espanola a la hegemonía tan fuerte de la cultura francesa, hegemonía combatida por muchos autores de la época. Sin embargo, el joven traductor no quería ocultar de ninguna manera el estado retrasado del pensamiento ilustrado español -por lo menos del pensamiento español que él conocía-. Recuérdese que ya en 1780 el hispanista Bertuch había dado a conocer en Alemania al Pensador mucho más moderno de Clavijo ${ }^{19}$. Almendingen no parece haber conocido esta traducción ni la del Fray Gerundio de Isla ${ }^{20}$.

Sobre la recepción de esta traducción parcial del TCU informa una resena publicada en la revista crítica más importante de la época, la Allgemeine deutsche Bibliothek de Nicolai (t. 109, I, 1792, p. 613-614). Esta reseña dada a luz en una revista muy favorable al movimiento ilustrado ${ }^{21}$ condena

19 En: F. J. Bertuch, Magazin der Spanischen und Portugiesischen Literatur, T. I., Weimar, 1780, pp. 35-96.

20 Existen dos traducciones; una de 1773 (¡del inglés!) y otra de 1777 (del español).

21 Cf. Jürgen Wilke, Literarische Zeitschriften des 18. Jahrhunderts (1688-1789), Teil II, Stuttgart, 1978 (Slg. Metzler), pp. 87-92. 
- a pesar de algunos elogios- el intento de traducir la obra de Feijoo. Aunque el crítico admite que la «biografía (!) del general (!) de los benedictinos españoles, no completamente desconocido en Alemania» interesaría también a los lectores alemanes, manifiesta la opinión siguiente: «Lo que ha sido nuevo y atractivo en España hace 60 años, ya no puede serlo entre los alemanes de hoy; puesto que nuestros buenos escritores nos comunican igualmente, incluso, de manera más libre y con más vigor, todas las verdades morales y políticas que el traductor nos presenta sacadas de su autor» (p. 613). Para el lector alemán, la obra de Feijoo ya no tiene sino valor histórico - opinión no tan diferente a la que reinaba en la España de los años 90, donde se interrumpió a partir de 1789 la publicación de sus obras ${ }^{22}$. En su reseña de los diferentes discursos, el crítico condena como (sumamente fastidiosas» las «Glorias de España», así que los n. II y III de la traducción. Los discursos IV y VII le parecen aceptables si fuesen presentados en resumen; el $\mathrm{n}$. $\mathrm{V}$ contiene pocas cosas verdaderas. El discurso VI es el más importante, aunque el crítico no comparte las valoraciones de Feijoo que serían inspiradas por prejuicios religiosos, sobre todo las de María Estuardo y Buchanan. Califica de (entretenidos» a los discursos VII y IX. EI n. IX (la crítica del maquiavelismo) es «muy bueno». El crítico protestante ${ }^{23}$ no puede tampoco aprobar el contenido de la "Carta a mi hermana». Le concede sólo un valor estético y lamenta “que su entusiasmo (!) escandaliza a veces al sano y recto sentido común»). (p. 614).

Resumiendo su juicio, el crítico constata que la traducción le «parece (!) ser buena»; critica la poca corrección del estilo de Almendingen. Pero como no ha leído el texto mismo de Feijoo, no se da cuenta de la transformación que éste ha experimentado por medio de las muchas omisiones. Al contrario, opina que hubiera sido mejor dar sólo breves extractos de la obra de Feijoo.

En el fondo, la crítica de nuestros días puede adoptar el punto de vista de la reseña: la recepción de la obra del benedictino español empezó demasiado tarde. Sus ideas ya no contribuian al verdadero enriquecimiento del pensamiento ilustrado alemán. Contrariamente a lo que iba a ocurrir con

22 La bibliografía de Cerra Suárez ya no indica ediciones de las obras de Feijoo a partir de esta fecha.

23 La reseña firmada « $\mathrm{Lw}$ » se escribió por un catedrático de la universidad de Rostock, Karsten, encargado de reseñar, entre otras cosas, los «escritos varios». (Cf. Gustav C. F. Parthey, Die Mitarbeiter an Friedrich Nicola'is Allgemeiner Deutscher Bibliothel (...), Berlín, 1842, p. 12). 
la obra de Cervantes y de Calderón durante la formación del Romanticismo, ya no entraban en el núcleo vital de la discusión intelectual de la época ${ }^{24}$.

Puede ser que el joven Almendingen se haya dado cuenta de este hecho y que, desanimado por la reseña negativa en una revista tan estimada, haya abandonado el proyeeto de publicar otros tomos más o por lo menos el segunde tomo que había prometido. Pero existe todavía otra razón que le impidió cumplir con su promesa. En 1792 terminó sus estudios jurídicos y se marchó a Amsterdam; en 1794 obtuvo una cátedra en Herborn y entró definitivamente en la carrera docente y administrativa. Esos deberes profesionales ya no le permitieron seguir con sus tareas literarias - que habia emprendido también en parte por razones económicas ${ }^{25}$-- En el transcurso de su vida, muy agitada por razones políticas, no volvió jamás a los trabajos literarios de su juventud.

Conclusión: Si en la Alemania del siglo XVIII no se ha desconocido por completo a Feijoo — valdría la pena coleccionar todas las menciones que se han hecho de èl en los diferentes libros que se referian a asuntos españoles ${ }^{26}$ - hay que constatar sin embargo, que el interés por lo español y el conocimiento lingüístico al respecto se dieron sólo en un momento en el que la actualidad del pensamiento —incluso médico— de Feijoo ya había pasado. Incluso los mismos traductores han puesto más de una vez graves reparos en cuanto a la actualidad del pensamiento de Feijoo.

Resulta del examen concreto de las diferentes traducciones parciales que se han hecho en la Alemania del siglo XVIII de algunos textos feijonianos que las notas compiladas en bibliografías y monografías al respecto de estas traducciones son poco exactas y han exagerado mucho el volumen de los textos traducidos.

Manfred Tietz

24 De la misma manera explicó Delpy el poco influjo que Feijoo ejerció en Francia (L'Espagne et l'esprit européen. L'oeuvre de Feijoo. (1725-1760), París, Hachette, 1936, pp. 302 ss.).

25 Merker, Almendingen, p. 272.

26 Para las menciones en algunas (!) revistas importantes de la Alemania ilustrada cf. Herbert O. Lyte, Spanish literature and Spain in some of the leading German Maga. sines of the second half of the eighteenth Century, Madison, 1932. 